\title{
IoT-Based Smart Building Environment Service for Occupants' Thermal Comfort
}

\author{
Herie Park $\mathbb{D}^{1}$ and Sang-Bong Rhee $\mathbb{D}^{2}$ \\ ${ }^{1}$ Automotive Lighting LED-IT Convergence Education, Yeungnam University, Gyeongsan 38541, Republic of Korea \\ ${ }^{2}$ Department of Electrical Engineering, Yeungnam University, Gyeongsan 38541, Republic of Korea \\ Correspondence should be addressed to Sang-Bong Rhee; rrsd@yu.ac.kr
}

Received 23 February 2018; Revised 14 April 2018; Accepted 23 April 2018; Published 21 May 2018

Academic Editor: Ka L. Man

Copyright (c) 2018 Herie Park and Sang-Bong Rhee. This is an open access article distributed under the Creative Commons Attribution License, which permits unrestricted use, distribution, and reproduction in any medium, provided the original work is properly cited.

\begin{abstract}
This paper presents an Internet of Things (IoT) platform for a smart building which provides human care services for occupants. The individual health profiles of the occupants are acquired by the IoT-based smart building, which uses the accumulated knowledge of the occupants to provide better services. To ensure the thermal comfort of the occupants inside the building, we propose a dynamic thermal model of occupants. This model is based on the heat balance equation of human body and thermal characteristics of the occupants. We implement this model in two smart building models with heaters controlled by a temperature and thermal comfort index using MATLAB/Simulink ${ }^{\circledR}$. The simulation results show that the thermal comfort-based control is more effective to maintaining occupants' thermal satisfaction and is therefore recommended for use providing human care services using IoT platforms in smart buildings.
\end{abstract}

\section{Introduction}

In a hyperconnected society, a human is linked to other people and machines, and machines are connected to other machines. This connectivity is formed by a physical and cybernetic linkage with the help of the sensing and communication technologies. These technologies make direct interactions among people, objects, and services that improve the productivity, efficiency, convenience, and security of our society [1]. The Internet of Things (IoT), big data, cloud computing, digital platforms, machine-to-machine (M2M) communication, artificial intelligence (AI), and machine learning are emerging technologies that support a hyperconnected society [2]. These smart technologies are applied to several domains including homes, factories, offices, transport systems, and other service and production areas. Objects and services are connected to individuals by personal communication devices and control applications that enable users to receive on-demand services.

Human care services are an example of these on-demand services. Human care services were initially explored in healthcare as a means to provide clinical services for patients who need help and care from others, such as infants and the elderly. Human care services include on-site treatment by caregivers at home or in clinical settings and long-distance treatment, also known as e-healthcare. The e-healthcare system improves the quality of patient care and reduces cost [3]. Since the e-healthcare system is composed of sensors, electronic health records, and communication protocols which are easily integrated on a commonly retailed personal device such as a smartphone, the scope of the e-healthcare services can be expanded to include the general public. For example, wearable devices such as a smartphone and a smart band have biosensors and health applications for measuring the user's heart rate, stress index, oxygen saturation, sleeping hours, step count, and so on. Wearable devices and several applications check these and additional user health conditions. The collected individual health records are sent to some form of personal healthcare manager through health applications via the smart devices. The user receives a feedback based on manager analysis. Therefore, the general public has a more accessibility to 


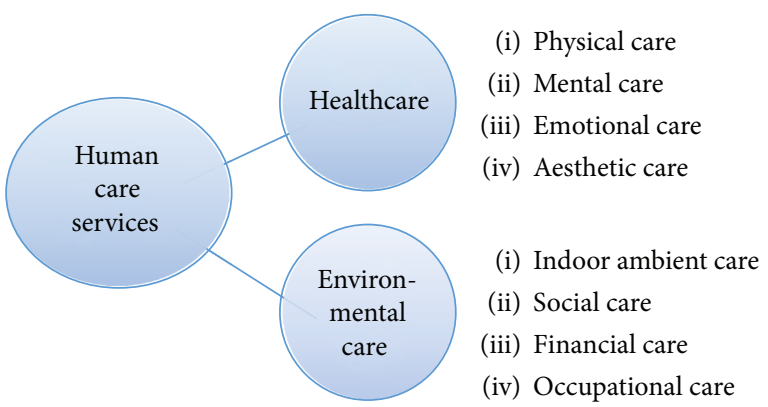

Figure 1: Types of human care services.

experience the e-healthcare services with the development of the related technology.

However, healthcare services are not limited to medical treatment. They can be extended to environmental management. Ulrich [4] proposed that psychological and social needs influence the medical outcomes of patients. He classified several environmental attributes including noise, light, windows, flooring materials, furniture arrangement, and air quality. These factors influence human sense, recognition, and emotion. Ulrich found that the environment can have a positive or a negative effect on patient recovery. This finding demonstrates the importance of ambient condition management. Since patients spend more time inside a building than outside, indoor environment could encourage patient recovery.

As the demand for quality of life increases, the wellness of individuals becomes more important than ever before. Thus, Figure 1 depicts how the scope and the range of human care services extend to incorporate the general public, not only for healthcare services, including physical, mental, emotional, and aesthetic cares, but also for environmental care, such as indoor ambient care, and social, financial, and occupational cares. Human care services can be applied to the ambient condition management of home, office, factory, and farm environments using a smartphone and other connected smart technology. For example, the ambient condition of a building, including lighting, temperature, and humidity, could be controlled by a smartphone that integrates IoT technologies. Recently, smart appliances have been linked to users and operated using signals sent from a smartphone or an unmanned repeater.

To improve ambient conditions for both patients and the general publics, multisensing and communication infrastructures are required. With the development of Internet-based technologies, it is easy to connect the related systems and individuals that are necessary to control the ambient building conditions. Indoor ambient care improves occupant comfort and convenience. Since the environmental conditions of a building are the product of interactions between the building's outdoor and indoor environments and subsystems, it is crucial to understand building physics in addition to occupant preferences. There have been many studies on using thermal analysis of buildings' inform design of heating, ventilation, and air-conditioning (HVAC) systems to predict energy consumption and to improve energy performance of the buildings [5-7]. However, there are few studies that concentrate on occupant activity as a meaningful influence on the thermal comfort of building occupants.

This study focuses on improving human care services provided by smart buildings as measured by increased occupant satisfaction with thermal conditions through the incorporation of considerations for occupant activity level in the analytical model. To accomplish this, Section 2 introduces the concept of the IoT platform of a smart building, which provides human care services including occupant comfort. Then, in Section 3, we suggest a thermal model of occupants and a control logic based on predicted mean vote (PMV). In Section 4, we integrate the proposed thermal comfort-based control logic into building models and obtain the indoor temperatures and the PMV values during different occupant activities. We compare the results of a PMV index-controlled heating system with those of a system thermally controlled by temperature. Finally, Section 5 relates our findings and conclusions.

\section{IoT Platform of a Smart Building}

A smart building is composed of automated building equipment and a communication infrastructure. The equipment includes HVAC systems, lighting systems, shading systems, window opening systems, elevators, air quality control systems, and other electrical devices and applications. Such dedicated equipment, categorized by functions, has been integrated with the smart building platform to facilitate real-time monitoring and controls using advanced technologies $[8,9]$. However, these systems are not directly connected to each other due to the different communication protocols specified by their manufacturers. To solve this communication problem, there have been many attempts to standardize the protocols and to integrate them on the same platform.

A smart building is connected to users and rapidly replies to instantaneous demands of the users. Figure 2 shows the basic three-layer architecture of a smart building IoT platform including data sensing, data processing, and data reproduction. As depicted in Figure 2, the first layer covers the data collection of sensors. The data are composed of the individual conditions of users, operation states of appliances and equipment, and indoor ambient conditions such as temperature, illuminance, and humidity. These are transferred via an Internet-connected gateway and stored in a dedicated big data cloud. The next layer is the data processing. Data is classified and processed for the controlling actuators of the building. Comfort-related actuators such as the HVAC system, lighting system, and blind system require data from individual users. In the reproducing layer, classified and processed data are reproduced as information pertaining to each interaction between occupant and appliance. The data is accumulated in time series. The accumulated data becomes knowledge of the users and informs system efficacy and efficiency enhancements, providing better services for the occupants.

As stated in the previous section, building conditions are the product of building interactions with their environments and subsystems. To control actuators with a focus on user comfort requires additional data processing that considers user activity and its influence on building conditions. 


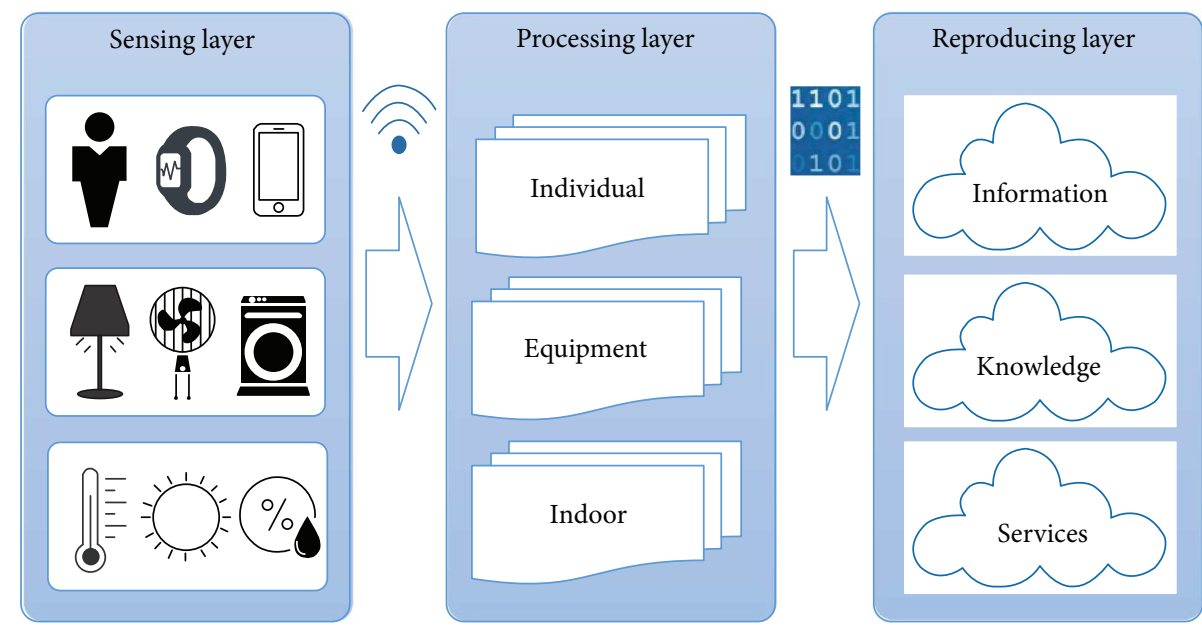

FIgURE 2: The basic architecture of an IoT platform in a smart building.

TABLE 1: Metabolic rates by activity.

\begin{tabular}{lccc}
\hline Class & Mean of metabolic heat $\left(\mathrm{W} / \mathrm{m}^{2}\right)$ & Metabolic heat $(\mathrm{W})$ & Example \\
\hline Resting & 65 & 115 & Resting \\
Low & 100 & 180 & Sitting at ease/standing \\
Moderate & 165 & 295 & Sustained hand/arm work \\
High & 230 & 415 & Intense work \\
Very high & 290 & 520 & Very intense to maximum activity \\
\hline
\end{tabular}

The following section proposes a thermal model of occupants that will improve human care services in IoT-based smart buildings.

\section{Thermal Comfort of Occupants}

3.1. Thermal Model of Occupants. The first step in conducting the thermal analysis of a building is to determine the internal heat gain of the building. Building internal heat gain is comprised of solar gain, metabolic heat gain, and heat gain produced by appliances. Metabolic heat gain, the heat gain profile of occupants, is a result of an occupant activity, such as resting, standing, and working. A heat gain model of occupants is deduced from the heat balance equation of the human body. The heat exchange of the human body in indoor conditions is expressed by the following equation $[10,11]$ :

$$
M=S+\mathrm{RL}+\mathrm{CL}+\mathrm{EL}
$$

where $M$ is the metabolic rate of generation of heat in the body $\left(\mathrm{W} / \mathrm{m}^{2}\right) ; S$ is the storage or the rate of net loss of heat due to lowering of body temperature $\left(\mathrm{W} / \mathrm{m}^{2}\right)$, counted negative when the body gains heat; $\mathrm{RL}$ is the rate of radiative loss of heat to the environment $\left(\mathrm{W} / \mathrm{m}^{2}\right)$, negative when the walls or other radiative surfaces are warmer than the skin; CL is the rate of convective loss of heat to the environment $\left(\mathrm{W} / \mathrm{m}^{2}\right)$, negative when the air is warmer than the skin; and EL is the rate of loss of heat by evaporation in the lungs and from the skin $\left(\mathrm{W} / \mathrm{m}^{2}\right)$.
Metabolic heat production expresses the rate of production of energy with time. Hence, $M$ represents the units of power (W). Since this term is related to surface area of the body, its unit is generally expressed by $\mathrm{W} / \mathrm{m}^{2}$. Moreover, the unit "MET" is sometimes used. " $1 \mathrm{MET}$ " is equivalent to $50 \mathrm{kcal} / \mathrm{m}^{2} / \mathrm{h}=58.2 \mathrm{~W} / \mathrm{m}^{2}$ and is said to be the metabolic rate of a seated person at rest [12]. The ISO 8996 standard [13] gives data for estimating the metabolic heat production of a human body. Table 1 shows the classification of metabolic rates by activity. It provides the fundamental support to ISO thermal comfort and other standards.

A static model is used as a conventional thermal model of occupants. In this model, the most important parameters are the number of occupants and their heat gains expressed as time series. However, this model does not reflect the fact that the metabolic heat flux varies over time, depending on both the occupants and their environment. Moreover, heat is transferred by multiple mechanisms, including conduction, convection, and radiation from body to environment. Therefore, we propose a dynamic thermal model of occupants to provide more accurate analysis and improve services. The heat transfer through body-clothing-environment can be expressed as follows:

$$
\phi_{\text {core }}=\phi_{\text {storage }}+\phi_{\text {evaporation }}+\phi_{\text {dissipation }}
$$

where $\phi_{\text {core }}$ is the metabolic heat gain of human body (W), $\phi_{\text {storage }}$ is the heat flux (W) for rising body temperature or stored heat flux within body, $\phi_{\text {evaporation }}$ is the heat flux (W) 
evaporated in the lungs and from the skin, and $\phi_{\text {dissipation }}$ is the dissipated heat flux (W) from body to environment. The body-clothing-environment heat transfer directly influences the thermal condition of environment, and this process is expressed as follows:

$$
\phi_{\text {dissipation }}=C_{\text {body }} \frac{d T_{\text {body }}}{d t}+\frac{1}{R_{\text {body }}}\left(T_{\text {body }}-T_{\text {indoor }}\right) \text {, }
$$

where $C_{\text {body }}$ is the thermal capacitance $(\mathrm{J} / \mathrm{K})$ of the human body. $R_{\text {body }}$ is the thermal resistance $\left({ }^{\circ} \mathrm{C} / \mathrm{W}\right)$ of the body. $T_{\text {body }}$ is the temperature of the body. $T_{\text {indoor }}$ is the temperature $\left({ }^{\circ} \mathrm{C}\right)$ of indoor environment. This is a first-order $R C$ thermal network model. For more detail, this model can be developed into a second-order model, as shown below:

$$
\begin{aligned}
\phi_{\text {dissipation }}= & \phi_{\text {body-clothing }}+\phi_{\text {clothing-indoor }}, \\
\phi_{\text {body-clothing }}= & C_{\text {body }} \frac{d T_{\text {body }}}{d t}+\frac{1}{R_{\text {body }}}\left(T_{\text {body }}-T_{\text {clothing }}\right), \\
\phi_{\text {clothging-indoor }}= & C_{\text {clothing }} \frac{d T_{\text {clothing }}}{d t} \\
& +\frac{1}{R_{\text {clothing }}}\left(T_{\text {clothing }}-T_{\text {indoor }}\right)
\end{aligned}
$$

where $\phi_{\text {body-clothing }}$ is the heat flux from body to clothing, and $\phi_{\text {clothing-indoor }}$ is the heat flux from clothing to indoor environment. $C_{\text {clothing }}$ and $R_{\text {clothing }}$ are the thermal capacitance $(\mathrm{J} / \mathrm{K})$ and the thermal resistance $\left({ }^{\circ} \mathrm{C} / \mathrm{W}\right)$ of the clothing of occupant, respectively. $T_{\text {clothing }}$ is the temperature $\left({ }^{\circ} \mathrm{C}\right)$ of clothing of the body.

The proposed model implies thermal characteristics of building occupants, which informs an understanding of the impact of individual thermal dynamics of building occupants. Factoring in the thermal dynamics of occupants enables a more accurate analysis of the thermal performance of a building. If this analysis is applied to the thermal control of a building, it can increase occupant comfort in terms of temperature conditions.

3.2. Thermal Comfort. Thermal comfort is an important indicator of overall building performance. It is defined as "that expression of mind which expresses satisfaction with the thermal environment" by the American Society of Heating, Refrigerating, and Air-Conditioning (ASHRAE) [14]. Since thermal comfort is personally determined and differs substantially between persons, it is not easy to quantify and analyze the value. Many researchers have investigated the parameters influencing thermal comfort in attempts to identify thermal comfort zones acceptable to the greatest number of people $[15,16]$.

The PMV model developed by Fanger in 1970s is the most well-known thermal comfort model. The PMV model is still applied to HVAC designs and referenced in recent studies [17-19]. To determine thermal comfort, this model evaluates six parameters: indoor air temperature, mean radiant temperature, relative humidity, air velocity, clothing, and metabolic rate of the occupant. The thermal comfort index is obtained as follows [20]:

$$
\mathrm{PMV}=[0.303 \cdot \exp (-0.036 \cdot M)+0.028] \cdot L,
$$

where

$$
\begin{aligned}
& L=(M-W)-3.05 \cdot 10^{-3} \cdot\left[5733-6.99 \cdot(M-W)-P_{\mathrm{a}}\right]-0.42 \cdot[(M-W)-58.15]-1.7 \cdot 10^{-5} \cdot M \cdot\left(5867-P_{\mathrm{a}}\right) \\
& -0.0014 \cdot M \cdot\left(34-t_{\mathrm{a}}\right)-3.96 \cdot 10^{-8} \cdot f_{\mathrm{cl}} \cdot\left[\left(t_{\mathrm{cl}}+273\right)^{4}-\left(\bar{t}_{\mathrm{r}}+273\right)^{4}\right]-f_{\mathrm{cl}} \cdot h_{\mathrm{c}} \cdot\left(t_{\mathrm{cl}}-t_{\mathrm{a}}\right), \\
& t_{\mathrm{cl}}=35.7-0.028 \cdot(M-W)-I_{\mathrm{cl}} \cdot 3.96 \cdot 10^{-8} \cdot f_{\mathrm{cl}} \cdot f_{\mathrm{cl}} \cdot\left[\left(t_{\mathrm{cl}}+273\right)^{4}-\left(\bar{t}_{\mathrm{r}}+273\right)^{4}\right]-I_{\mathrm{cl}} \cdot f_{\mathrm{cl}} \cdot h_{\mathrm{c}} \cdot\left(t_{\mathrm{cl}}-t_{\mathrm{a}}\right) \text {, } \\
& h_{\mathrm{c}}=\left\{\begin{array}{c}
2.38 \cdot\left|t_{\mathrm{cl}}-t_{\mathrm{a}}\right|^{0.25}, \quad \text { if } 2.38 \cdot\left|t_{\mathrm{cl}}-t_{\mathrm{a}}\right|^{0.25}>12.1 \sqrt{v_{\mathrm{ar}}}, \\
12.1 \sqrt{v_{\mathrm{ar}}}, \quad \text { if } 2.38 \cdot\left|t_{\mathrm{cl}}-t_{\mathrm{a}}\right|^{0.25} \leq 12.1 \sqrt{v_{\mathrm{ar}}},
\end{array}\right. \\
& f_{\mathrm{cl}}=\left\{\begin{array}{cc}
1+1.29 \cdot I_{\mathrm{cl}}, & \text { if } I_{\mathrm{cl}} \leq 0.078 \\
1.05+0.645 \cdot I_{\mathrm{cl}}, & \text { if } I_{\mathrm{cl}}>0.078
\end{array}\right. \\
& P_{\mathrm{a}}=h_{\mathrm{r}} \cdot 6.1094 \cdot \exp \left[\frac{\left(17.625 \cdot t_{\mathrm{a}}\right)}{\left(t_{\mathrm{a}}+243.04\right)}\right] \text {, }
\end{aligned}
$$

where PMV is the value of the predicted mean vote index, $M$ is the metabolic rate $\left(\mathrm{W} / \mathrm{m}^{2}\right), L$ is the thermal load of human body $\left(\mathrm{W} / \mathrm{m}^{2}\right), W$ is the rate of mechanical work $\left(\mathrm{W} / \mathrm{m}^{2}\right)$ which is 0 in most activities, $P_{\mathrm{a}}$ is the partial water vapor pressure $(\mathrm{Pa}), t_{\mathrm{a}}$ is the indoor air temperature $\left({ }^{\circ} \mathrm{C}\right), t_{\mathrm{cl}}$ is the surface temperature of clothing $\left({ }^{\circ} \mathrm{C}\right), \bar{t}_{\mathrm{r}}$ is the mean radiant 
TABLE 2: PMV index.

\begin{tabular}{lc}
\hline Index & Explanation \\
\hline-3 & Cold \\
-2 & Cool \\
-1 & Slightly cool \\
0 & Neutral \\
1 & Slightly warm \\
2 & Warm \\
3 & Hot \\
\hline
\end{tabular}

temperature $\left({ }^{\circ} \mathrm{C}\right), f_{\mathrm{cl}}$ is the clothing surface area factor, $I_{\mathrm{cl}}$ is the thermal resistance of clothing $\left(\mathrm{m}^{2 \circ} \mathrm{C} / \mathrm{W}\right), h_{\mathrm{c}}$ is the convective heat transfer coefficient $\left(\mathrm{W} / \mathrm{m}^{2{ }^{\circ}} \mathrm{C}\right), v_{\mathrm{ar}}$ is the air velocity $(\mathrm{m} / \mathrm{s})$, and $h_{\mathrm{r}}$ is the relative humidity (\%). The PMV index is represented by 7 points from -3 to 3 as summarized in Table 2. The optimal temperature is achieved when PMV is zero, indicating thermally neutral sensation, during different human activity level [21].

3.3. PMV-Based Control Algorithm. Thermal condition of the indoor environment is determined by maintaining a PMV in the range of -0.2 to 0.2 . This range is one of the recommended thermal environments given by ISO EN 7730 and CEN standard EN 15251 [22-24]. These standards suggested the PMV value between -0.2 and 0.2 for a high level of expectation and for spaces occupied by very sensitive and fragile persons. Since our study is focused on human care services including a healthcare service, we should consider the highest limitations on thermal comfort. It is why we limited the range of PMV from -0.2 to 0.2 . The six parameters of PMV are measured by sensors installed in a target space and by personal wearable devices.

The proposed PMV-based control algorithm consists of following sequence of events. First, the presence of an occupant is detected to judge the necessity of operation of heating/cooling systems. If an occupant is detected inside a target space, the PMV index is calculated by using (5). In this step, we use metabolic heat gain of a human body obtained by the proposed thermal model of occupants. Since the thermal conditions of the space are controlled by the PMV index, by extension, the control command signals used to operate thermal systems such as heating and air-conditioning are also determined by the PMV value. For example, during winter season, a heating system operates. If the PMV value is less than -0.2 , a command signal for a heating system is given as "1." Else, the command signal is given as "0." During summer season, a cooling system is used. If the PMV value is greater than 0.2 , a command signal to operate the cooling system is given as "1." Otherwise, the command is " 0 ." A PMV-based control is expected to make occupants more comfortable and satisfied than a temperature-based control.

\section{Case Study}

To investigate the feasibility of thermal modeling of occupants and the influence of metabolic heat gain inside a building, we integrated the proposed thermal model of occupants with a simple $R C$-lumped building model using MATLAB/Simulink. Then, the metabolic heat gain obtained by the proposed thermal model, which considered different occupant activities, was applied to the building model as a heat source. The thermal conditions of the building, as controlled by temperature and by the PMV index, were compared to determine which control algorithm is more useful for providing human care services in smart buildings.

Table 3 describes the parameters of a building model. These parameters were used in the modelling process and the simulation of our case study. As the weather condition, we selected a cold weather. The outdoor temperature is varied against time and is given as a sinusoidal function of which amplitude is 3 . The temperature varies from -3 to 3 . In addition, we considered the case where the heating system is required to achieve a certain range of indoor temperature or PMV values.

4.1. Metabolic Heat Gain of Occupants. To demonstrate how metabolic heat affects the indoor temperature of a building, we created a simple scenario of activities for a building occupant. The occupant stays in the building in a resting mode for most of the daily 24 -hour period, dissipating metabolic heat of $115 \mathrm{~W}$. For two hours and forty minutes, from 16:00 to $18: 40$, the occupant works with their hands and arms. This activity level increases dissipated metabolic heat gain to $295 \mathrm{~W}$. We applied this scenario to the proposed thermal model of occupants. We developed two models in MATLAB/Simulink: (1) a static model and (2) a dynamic model. Figure 3 shows the developed thermal models of occupants integrated with a building model. The first model is a conventional model used for thermal analysis of buildings. It does not account for the thermal dynamics of users. The second model is the dynamic model proposed in Section 3. To describe the thermal characteristics of the human body, we used global thermal resistance and global thermal capacitance values of a human body as $30 \mathrm{~W} / \mathrm{m} \cdot \mathrm{K}$ and $3770 \mathrm{~J} / \mathrm{kg} / \mathrm{K}$, respectively.

After developing these models, we compared the influence of the heat gain generated by a static model and a dynamic model following the given occupant activity scenario inside the building. Figure 4 shows the simulated static and dynamic heat flux $\left(\phi_{\text {dissipation }}\right)$ dissipated by the occupant due to their specific activity. The heat gain simulated with a static model follows a constant value for each activity. In a resting mode, the metabolic heat gain of $115 \mathrm{~W}$ is dissipated by the occupant. While the occupant sustainably works with their arms and hands, the heat of $295 \mathrm{~W}$ is dissipated. The static model only shows a heat gain profile of the occupant in a steady state. However, the dynamic model describes a heat gain profile in a steady state and a transient state since this model considers thermal resistance and capacitance values of the occupant. In this model, heat is charged and discharged according to thermal characteristics of the occupant.

Since the occupant is thermally linked to the building, the activity of the occupant should be considered in the management of the thermal comfort and energy use of the building. Given the generated metabolic heat flux, the temperature 
Table 3: A brief description of the used building.

\begin{tabular}{lc}
\hline Parameters & Description \\
\hline Building type & Residential building \\
Floor area & Modular space area $=52.8 \mathrm{~m}^{2}$ \\
Dimension and heights & $16 \mathrm{~m} \times 3.3 \mathrm{~m}$; floor-to-ceiling $=4 \mathrm{~m}$ \\
Wall & Thickness $=0.2 \mathrm{~m} ;$ density $=1920 \mathrm{~kg} / \mathrm{m}^{3} ;$ specific heat $=835 \mathrm{~J} / \mathrm{kg} / \mathrm{K} ;$ thermal conductivity $=0.038 \mathrm{~W} / \mathrm{m} / \mathrm{K}$ \\
Window & Thickness $=0.01 \mathrm{~m} ;$ density $=2700 \mathrm{~kg} / \mathrm{m}^{3} ;$ specific heat $=840 \mathrm{~J} / \mathrm{kg} / \mathrm{K} ;$ thermal conductivity $=0.78 \mathrm{~W} / \mathrm{m} / \mathrm{K}$ \\
Operating hours & 24 hours \\
Metabolic heat gain & Resting mode: $115 \mathrm{~W}$ \\
Outdoor temperature & $-3^{\circ} \mathrm{C} \sim 3^{\circ} \mathrm{C}$ \\
\hline
\end{tabular}

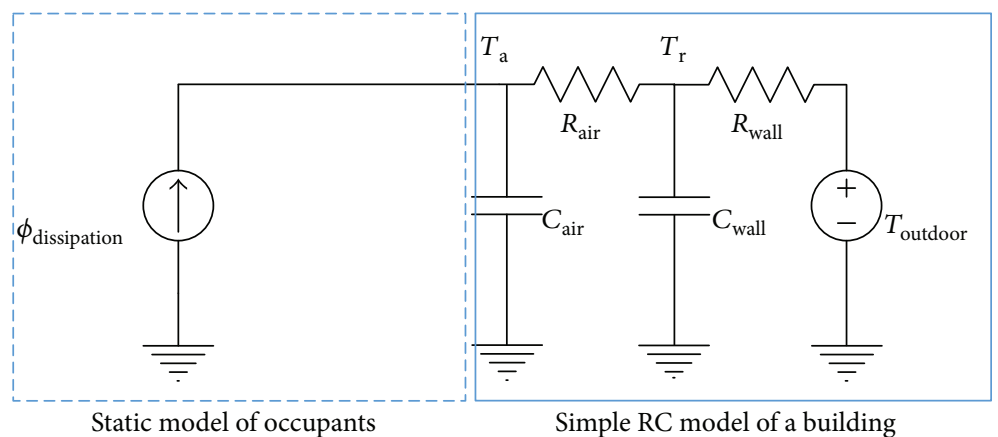

(a)

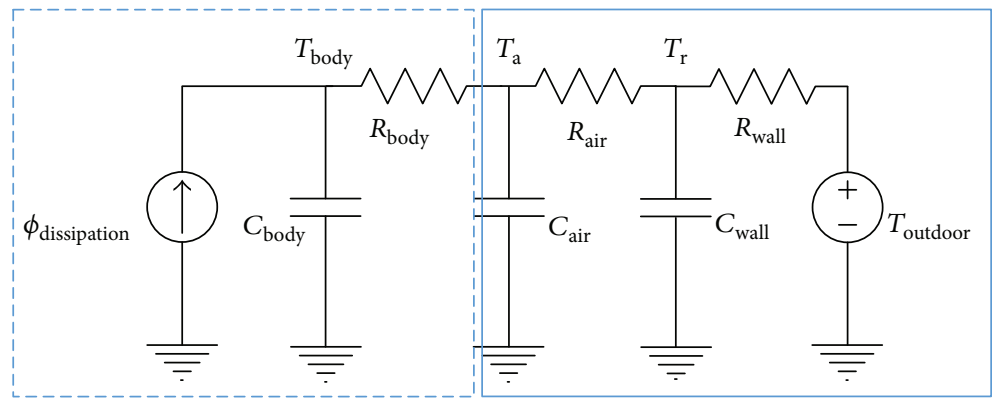

Dynamic model of occupants

Simple RC model of a building

(b)

FIGURE 3: Thermal models of occupants integrated in a building model: (a) static model and (b) dynamic model.

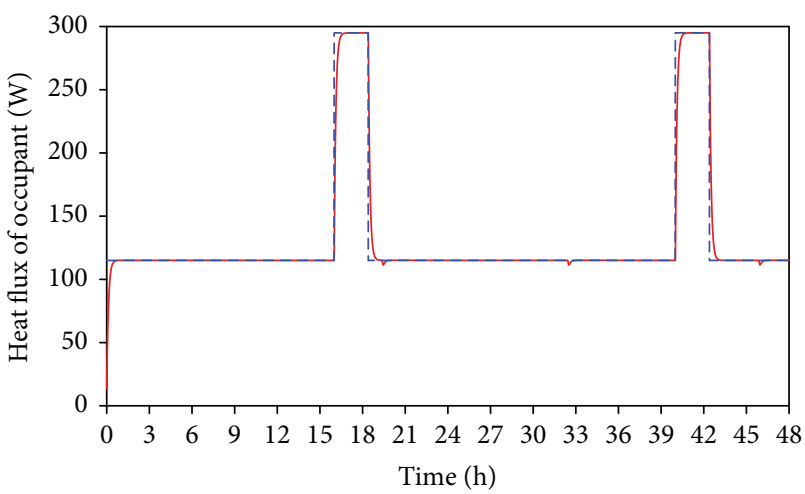

FIGURE 4: Heat flux of the occupant (blue broken line: static model; red line: dynamic model).

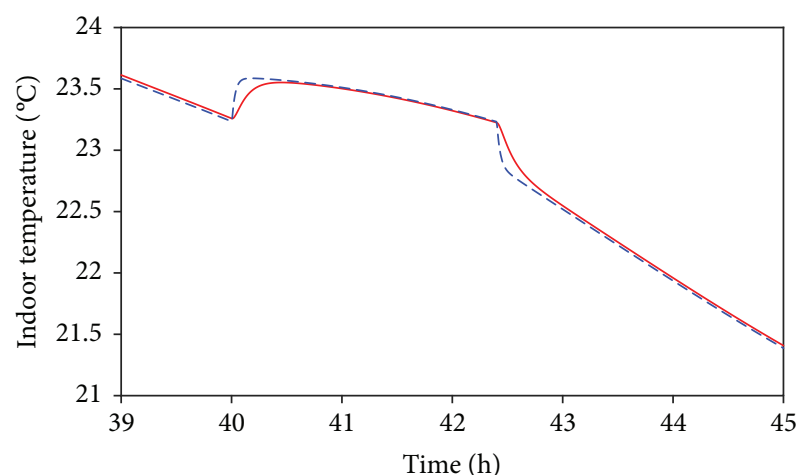

FIgURE 5: Indoor temperature of the building (blue broken line: static model; red line: dynamic model). 


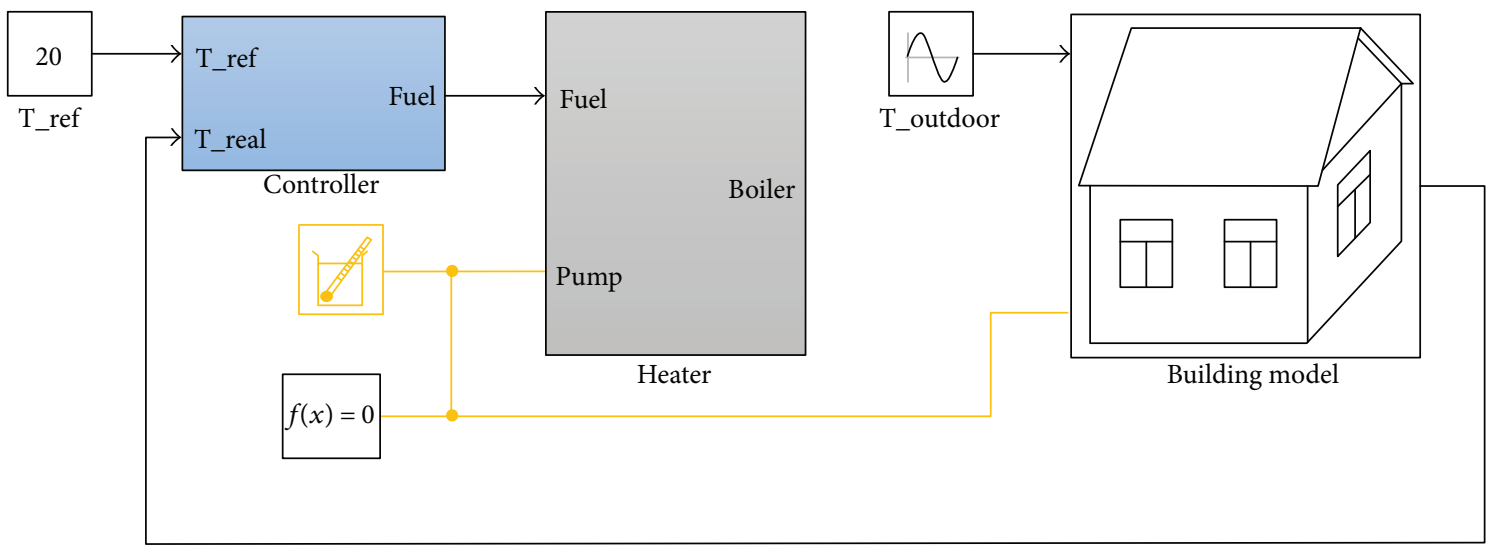

(a)

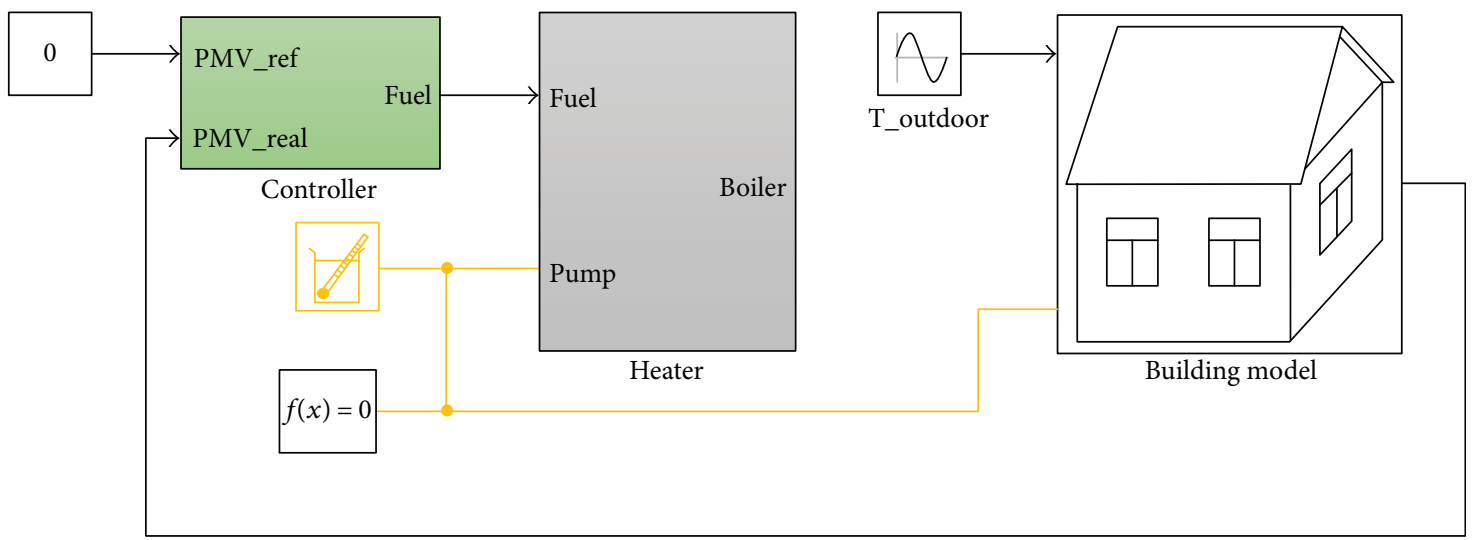

(b)

Figure 6: Important features of the building and its subsystems: (a) temperature-based controller and (b) PMV-based controller.

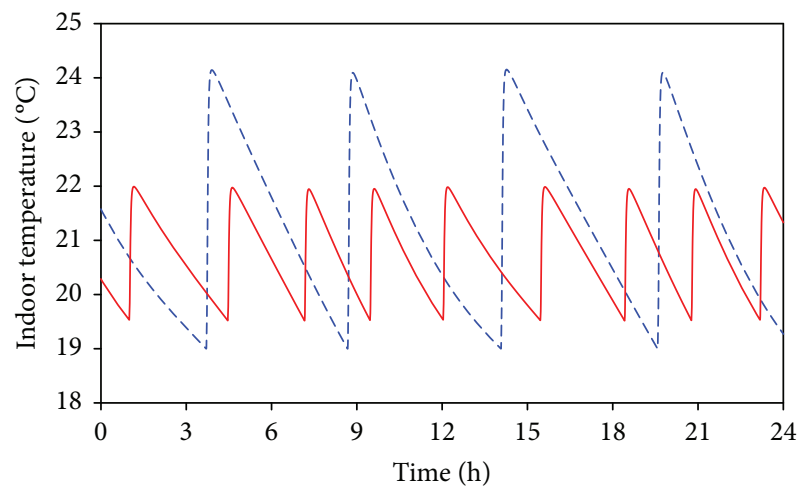

(a)

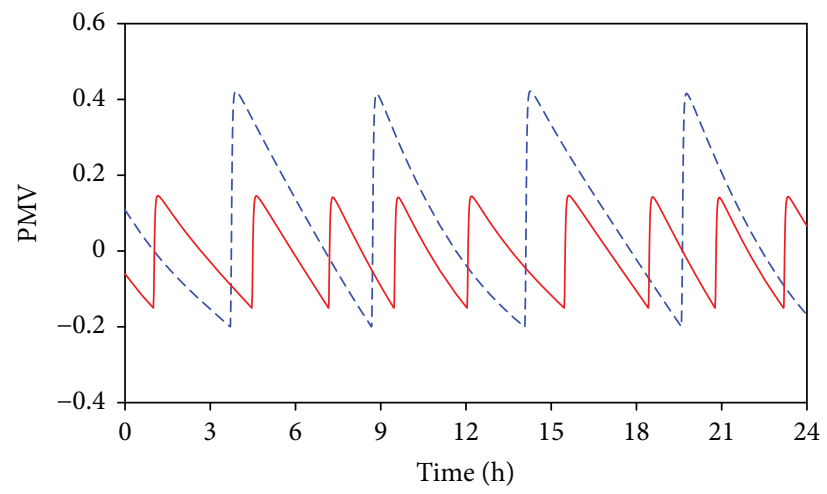

(b)

Figure 7: Temperature and PMV: (a) $T_{\mathrm{a}}$ and (b) PMV (blue broken line: model 1; red line: model 2).

evolution of the building is obtained as shown in Figure 5. The indoor temperature of the building $\left(T_{\mathrm{a}}\right)$ is influenced by the occupant, demonstrating that the occupant can be considered a heat source of the building. The indoor temperature globally decreases during in the period from hour 39 to hour 45 . This period is the equivalent of hour 15 to hour 21 of the second 24-hour cycle.

Despite the global decrease, note the significant temperature variation during the period from 40:00 to 42:40 or 16:00 to $18: 40$ of the second daily period, of the simulation. In the scenario, this is the period when the occupant continuously works with their arms and hands. While $T_{\mathrm{a}}$ obtained from the static model shows the thermal dynamics of the building, $T_{\mathrm{a}}$ given by the dynamic model depicts the dynamics of the occupant as well as that of the building. This demonstrates that the dynamic model describes a more accurate temperature evolution of the building. Consequently, the proposed model performs better, providing a more detailed thermal analysis, enabling an improved control strategy for thermal systems and increasing the thermal comfort of occupants. 


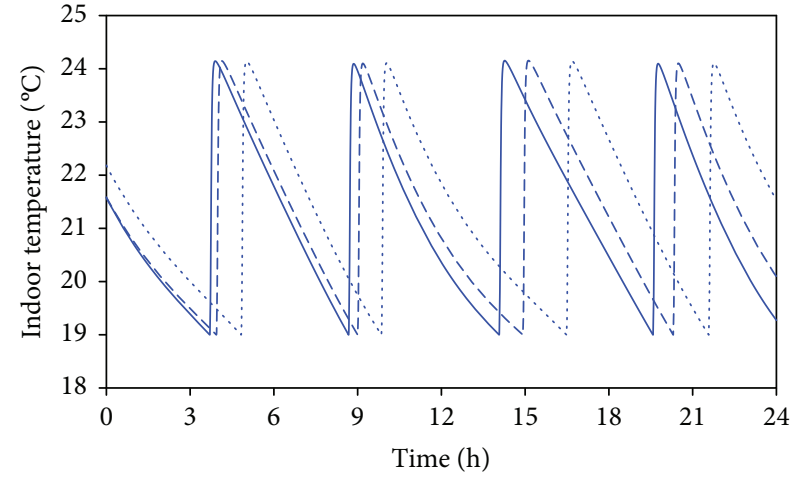

(a)

Figure 8: Temperature and PMV of model 1 with different $\phi_{\text {dissipation }}$ dotted line: $155 \mathrm{~W}$ ).

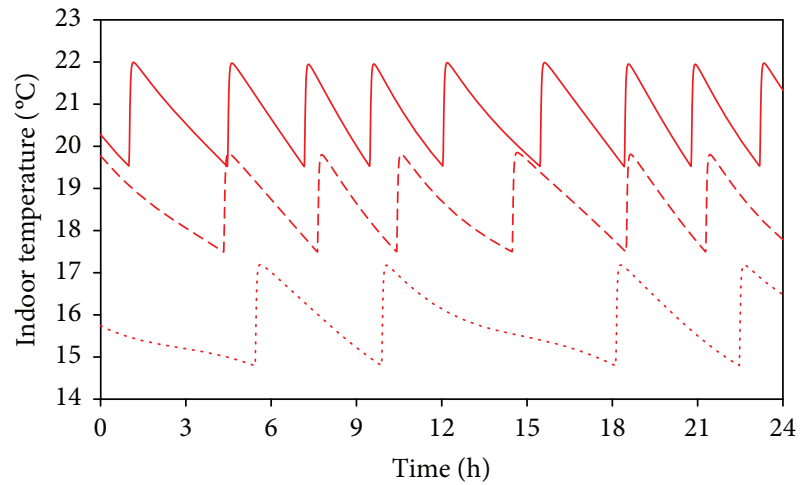

(a)

FIGURE 9: Temperature and PMV of model 2 with different $\phi_{\text {dissipation }}$ line: $155 \mathrm{~W})$.

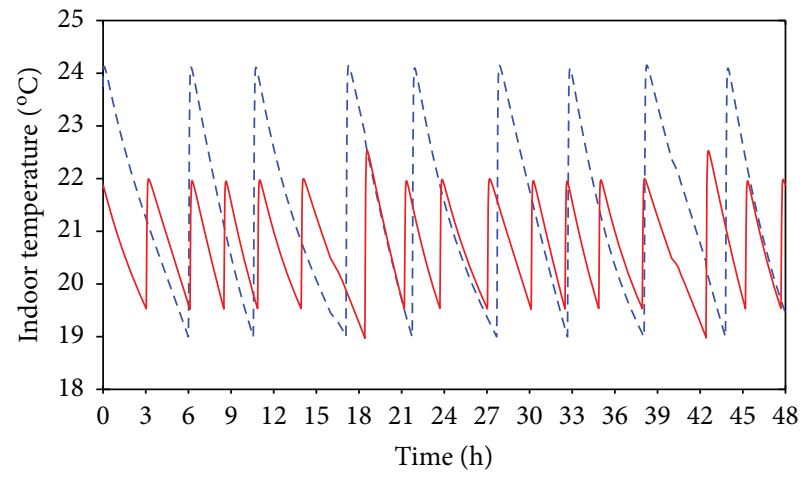

(a)

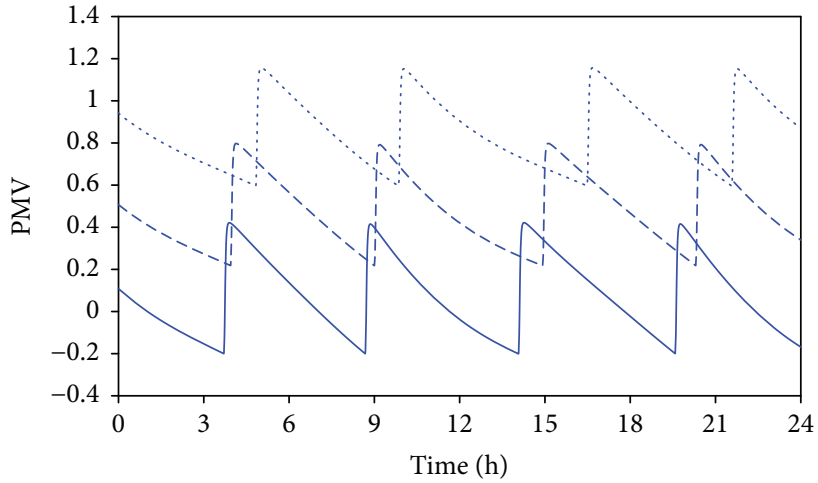

(b)

(a) $T_{\mathrm{a}}$ and (b) PMV (blue line: $115 \mathrm{~W}$; blue broken line: $135 \mathrm{~W}$; blue

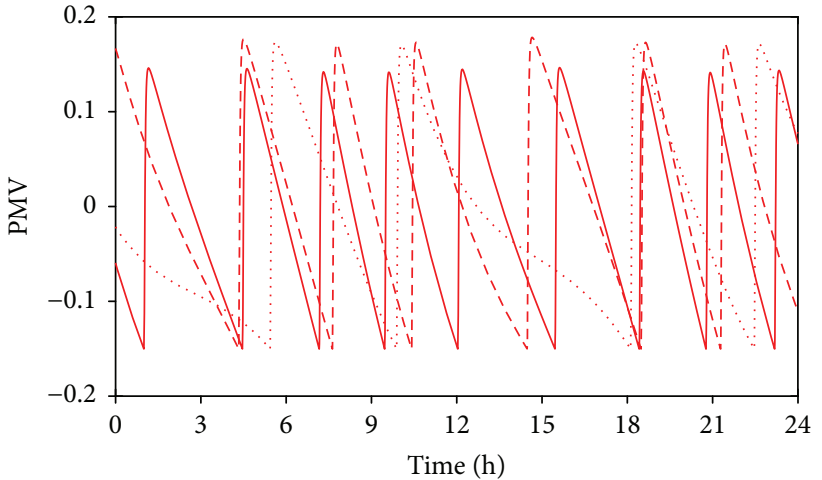

(b)

: (a) $T_{\mathrm{a}}$ and (b) PMV (red line: $115 \mathrm{~W}$; red broken line: $135 \mathrm{~W}$; red dotted

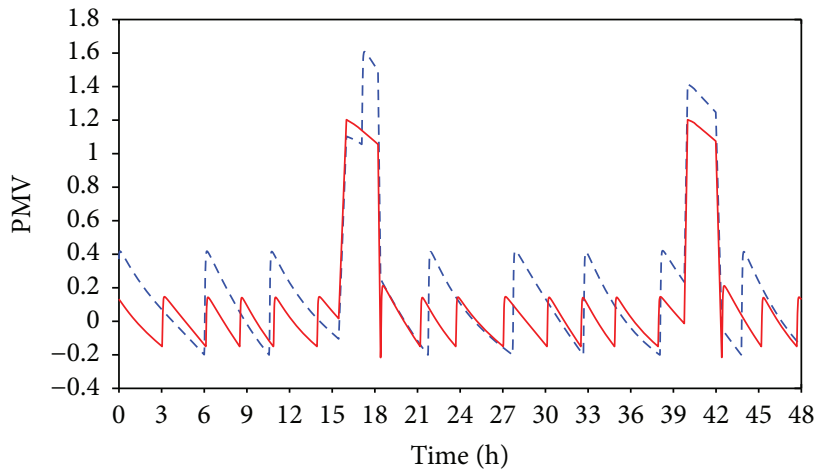

(b)

Therefore, we suggest integrating this model with IoT-based smart building environment services for occupants' comfort.

4.2. PMV-Based Thermal Control. The general features of the smart building, heating system, and controller for each of the two models are illustrated in Figure 6. The first model has a heater with a temperature-based controller. Model 1 controls the heating system based on a reference value for indoor temperature. Model 2 achieves a PMV-led control for thermal comfort of building occupants. Model 2 maintains a PMV value in the range of -0.2 to 0.2 as explained in Section 3.3. 
Thermal controls based on temperature and PMV are both achieved based on the scenario of an occupant inside the building. Figure 7 shows the results of $T_{\mathrm{a}}$ of the building and the PMV of an occupant in a resting mode. $T_{\mathrm{a}}$ of model 1 is controlled between $19^{\circ} \mathrm{C}$ and $24^{\circ} \mathrm{C}$, and the value of PMV of model 1 follows the variation of $T_{\mathrm{a}}$, ranging between -0.2 and 0.4 . Model 2 bases control of the heater on the PMV index. If the PMV is smaller than its reference value, the heater is activated. Then, $T_{\mathrm{a}}$ increases. If the PMV value is greater than its reference value, the heater ceases operations. Consequently, $T_{\mathrm{a}}$ decreases. In both models, the indoor temperature and the PMV interact to each other because these are directly related to the operation of the heating system. Therefore, the trend of indoor temperature evolution is similar to that of PMV.

However, the heat dissipation of the occupant does not directly affect $T_{\mathrm{a}}$ in model 1 because the heater of model 1 operates in accordance with $T_{\mathrm{a}}$ as shown in Figure 8 . Although the heat dissipation levels of the occupant become different as $115 \mathrm{~W}, 135 \mathrm{~W}$, and $155 \mathrm{~W}$, the range of $T_{\mathrm{a}}$ does not change. Since thermal condition of the building is controlled by temperature, it is reasonable to obtain a fixed range of $T_{\mathrm{a}}$ irrelevant to any activities of the occupant. Moreover, the considered metabolic heat gains of $115 \mathrm{~W}, 135 \mathrm{~W}$, and $155 \mathrm{~W}$ are small enough to keep the temperature within the reference between $19^{\circ} \mathrm{C}$ and $24^{\circ} \mathrm{C}$. It is why the temperature does not surpass $24^{\circ} \mathrm{C}$ and that there was no requirement for a cooling system. However, it would be required to integrate the cooling system for the case where heat dissipation of occupants is high enough.

In the context of the PMV index, stronger activities cause higher metabolic heat dissipation and leads to different levels of occupant thermal comfort. Therefore, with higher metabolic heat, the value of PMV becomes higher in the same temperature condition of the building. Consequently, thermal comfort of the occupant is not assured when applying model 1 with a temperature-based controller.

Contrary to model 1, occupant thermal comfort is preferentially assured in model 2 which implements PMV-based control logic. Figure 9 depicts the $T_{\mathrm{a}}$ and PMV obtained in model 2. While the range of $T_{\mathrm{a}}$ is fixed from $19^{\circ} \mathrm{C}$ to $24^{\circ} \mathrm{C}$ for all three activities in model 1 , the range of $T_{\mathrm{a}}$ in model 2 shifts to account for the different heat dissipation levels of each activity. In model 2, the PMV range is fixed. To achieve PMV values within the optimum range of -0.2 and 0.2 , the operation of the heater is controlled as specified in Section 3.3. Since greater heat dissipation induces the occupant to feel hotter, the range of $T_{\mathrm{a}}$ is lower than when less metabolic heat dissipation occurs. This is demonstrated by the observation that the higher the metabolic heat, the lower the $T_{a}$, while lower metabolic heat values result in higher $T_{\mathrm{a}}$. Since the heater operates in accordance with the PMV of the occupant, the ranges of the obtained indoor temperature under different quantity of metabolic heat gain of the occupant are differently determined while the ranges of the PMV are similar to each other. Moreover, the indoor temperature decreases when the heater is turned off because the amplitude of the outdoor temperature is between -3 and $3^{\circ} \mathrm{C}$, less than the indoor temperature.
We also implemented a scenario with different occupant activities in 24-hour cycles. The occupant rests during most of the daily cycle and dissipates metabolic heat of $115 \mathrm{~W}$. However, from 16:00 to 18:40 of each 24 hour period, the occupant performs a low energy activity and dissipates metabolic heat of $180 \mathrm{~W}$. Figure 10 presents the $T_{\mathrm{a}}$ and PMV values for the two models over the course of two consecutive 24-hour cycles of the previously described scenario. The impact of increased occupant heat dissipation is observed in the slight increase in $T_{\mathrm{a}}$ during occupant activity, despite a globally decreasing trend of $T_{\mathrm{a}}$ in both models. Analogously, the increased heat gain also raises $T_{\mathrm{a}}$ for both models under a globally increasing trend of $T_{\mathrm{a}}$. Note that the PMV of model 1 peaks farther from the ideal, neutral zero point than does model 2. As discussed before, these results show that increased satisfaction with human care services is achieved when comfort-based actuators are controlled on the basis of comfort-based indices.

\section{Conclusions}

To increase comfort and convenience, the scope of human care services has expanded to include ambient condition management. With the help of the sensing and communication technologies, individual occupant health profiles could be acquired and accumulated in an IoT-based smart building. The profiles would be analysed for occupant information, and the applied knowledge would enable improved services to be implemented. To achieve thermal comfort for building occupants, we proposed a dynamic thermal model of occupants based on the heat balance equation of human body and thermal characteristics of the occupants. We implemented this model in two smart building models with heaters controlled by temperature and by the PMV value, the most widely used thermal comfort index. The simulation results showed that PMV-based thermal control improves occupant thermal satisfaction when compared to temperature-based thermal control. Therefore, we suggest that PMV-based thermal control be integrated into the IoT-based smart building platform to enable improved human care services.

\section{Data Availability}

The data used to support the findings of this study are available from the corresponding author upon request.

\section{Conflicts of Interest}

The authors declare that they have no conflicts of interest.

\section{Acknowledgments}

This research was supported by the Basic Science Research Program through the National Research Foundation of Korea (NRF) funded by the Ministry of Education (2017R1D1A3B03035693). In addition, this work was supported by the Brain Korea 21 Plus Program (22A2015 2113298) funded by the National Research Foundation of Korea (NRF). 


\section{References}

[1] S. Tang, V. Kalavally, K. Y. Ng, and J. Parkkinen, "Development of a prototype smart home intelligent lighting control architecture using sensors onboard a mobile computing system," Energy and Buildings, vol. 138, pp. 368-376, 2017.

[2] Y. Liu and X. Xu, "Industry 4.0 and cloud manufacturing: a comparative analysis," Journal of Manufacturing Science and Engineering, vol. 139, no. 3, article 034701, p. 8, 2017.

[3] K. Saleem, A. Derhab, J. Al-Muhtadi, and B. Shahzad, "Human-oriented design of secure machine-to-machine communication system for e-healthcare society," Computers in Human Behavior, vol. 51, pp. 977-985, 2015.

[4] R. S. Ulrich, "Effects of healthcare environmental design on medical outcomes," in International Academy for Design and Health: Proceedings of the Second International Conference on Health and Design, pp. 49-59, Sweden: Svensk Byggtjanst, 2001.

[5] A. T. Nguyen, S. Reiter, and P. Rigo, "A review on simulationbased optimization methods applied to building performance analysis," Applied Energy, vol. 113, pp. 1043-1058, 2014.

[6] W. I. W. M. Nazi, M. Royapoor, Y. Wang, and A. P. Roskilly, "Office building cooling load reduction using thermal analysis method - a case study," Applied Energy, vol. 185, pp. 15741584, 2017.

[7] S. Heinen, W. Turner, L. Cradden, F. McDermott, and M. O'Malley, "Electrification of residential space heating considering coincidental weather events and building thermal inertia: a system-wide planning analysis," Energy, vol. 127, pp. 136-154, 2017.

[8] C. Fan and F. Xiao, "Assessment of building operational performance using data mining techniques: a case study," Energy Procedia, vol. 111, pp. 1070-1078, 2017.

[9] N. Aste, M. Manfren, and G. Marenzi, "Building automation and control systems and performance optimization: a framework for analysis," Renewable and Sustainable Energy Reviews, vol. 75, pp. 313-330, 2017.

[10] D. Brunt, "Some physical aspects of the heat balance of the human body," Proceedings of the Physical Society, vol. 59, no. 5, pp. 713-726, 1947.

[11] H. Park, "Dynamic thermal modeling of electrical appliances for energy management of low energy buildings," in Electric Power, Université de Cergy-Pontoise, Cergy Pontoise, France, 2013.

[12] G. Havenith, I. Holmér, and K. Parsons, "Personal factors in thermal comfort assessment: clothing properties and metabolic heat production," Energy and Buildings, vol. 34, no. 6, pp. 581-591, 2002.

[13] ISO 8996, Ergonomics of the Thermal EnvironmentsDetermination of Metabolic Heat Production, ISO, Geneva, 1989.

[14] ASHRAE 55, Thermal Environmental Conditions for Human Occupancy, American Society of Heating Refrigerating AirConditioning Engineers, Atlanta, GA, USA, 2004.

[15] J. Hensen, "On the thermal interaction of building structure and heating and ventilation system, [Ph.D. Thesis]," Technische Universiteit Eindhoven, Eindhoven, Netherlands, 1991.

[16] H. Zhang, "Human thermal sensation and comfort in transient and non-uniform thermal environments, [Ph.D. Thesis]," University of California, Berkeley, CA, USA, 2003.
[17] L. Zampetti, M. Arnesano, and G. M. Revel, "Experimental testing of a system for the energy-efficient sub-zonal heating management in indoor environments based on PMV," Energy and Buildings, vol. 166, pp. 229-238, 2018.

[18] Z. Xu, G. Hu, C. J. Spanos, and S. Schiavon, "PMV-based event-triggered mechanism for building energy management under uncertainties," Energy and Buildings, vol. 152, pp. 73-85, 2017.

[19] R. Holopainen, P. Tuomaala, P. Hernandez, T. Hakkinen, K. Piira, and J. Piippo, "Comfort assessment in the context of sustainable buildings: comparison of simplified and detailed human thermal sensation methods," Building and Environment, vol. 71, pp. 60-70, 2014.

[20] P. Fanger, Thermal Comfort: Analysis and Applications in Environmental Engineering, Danish Technical Press, Copenhagen, 1970.

[21] ISO7730, Moderate Thermal Environments - Determination of the PMV and PPD Indices and Specification of the Conditions for Thermal Comfort, ISO, Geneva, 1984.

[22] ISO7730, Ergonomics of the Thermal Environment Analytical Determination and Interpretation of Thermal Comfort Using Calculation of the PMV and PPD Indices and Local Thermal Comfort Criteria, ISO, Geneva, 2005.

[23] F. Nicol and M. Wilson, "An overview of the European standard EN 15251," in Proceedings on Adapting to Change: New Thinking Comfort, pp. 1-13, Cumberland Lodge, Windsor, UK, April 2010.

[24] EN15251, Indoor Environmental Input Parameters for Design and Assessment of Energy Performance of Buildings - Addressing Indoor Air Quality, Thermal Environment, Lighting and Acoustics, European Committee for Standardization, Brussels, 2007. 


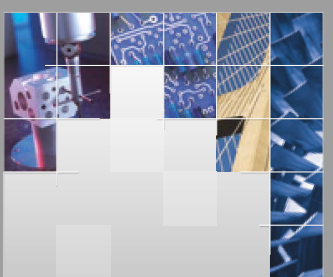

\section{Enfincering}
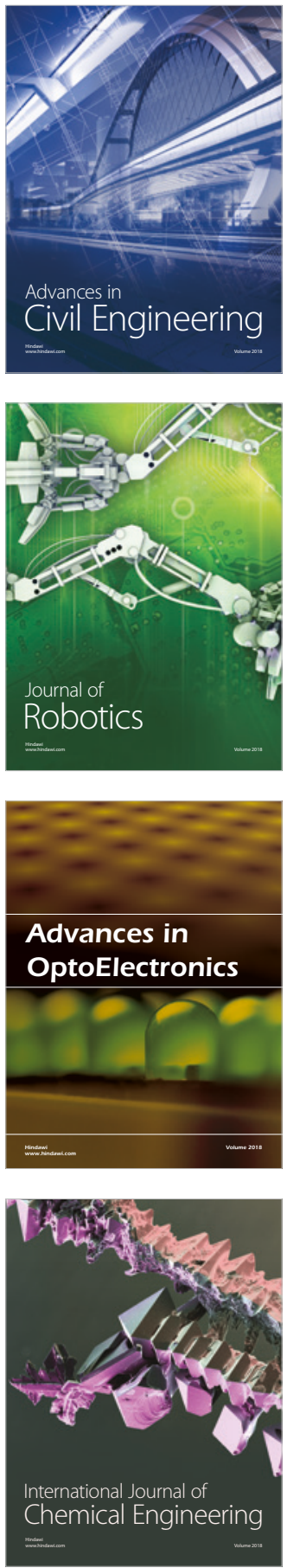

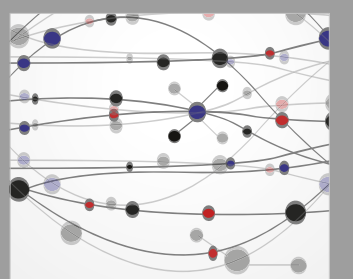

\section{Rotating \\ Machinery}

The Scientific World Journal

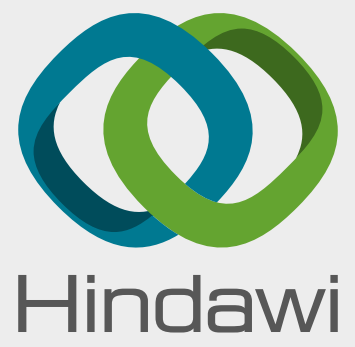

Submit your manuscripts at

www.hindawi.com
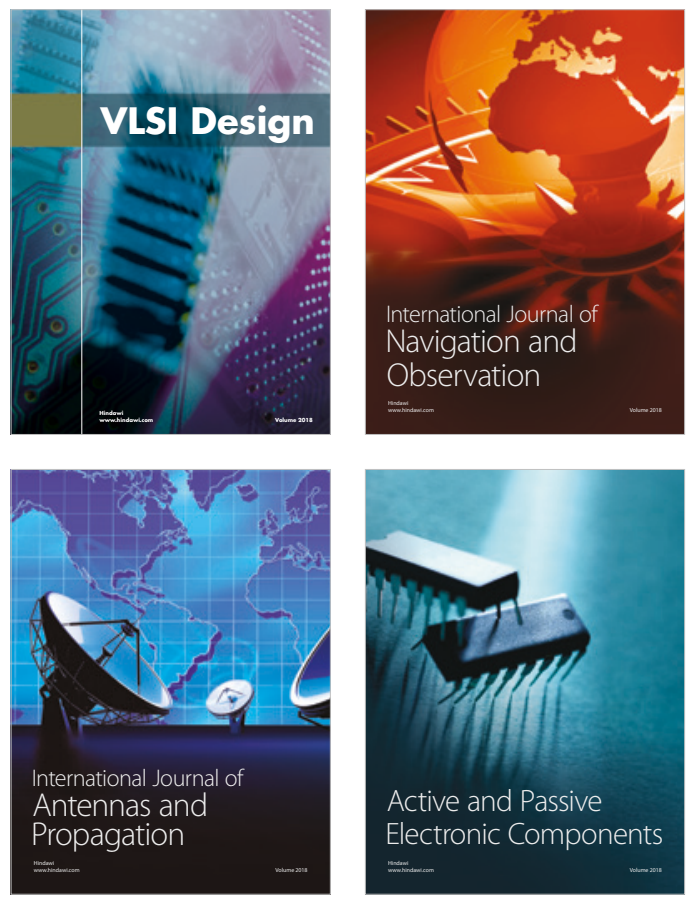
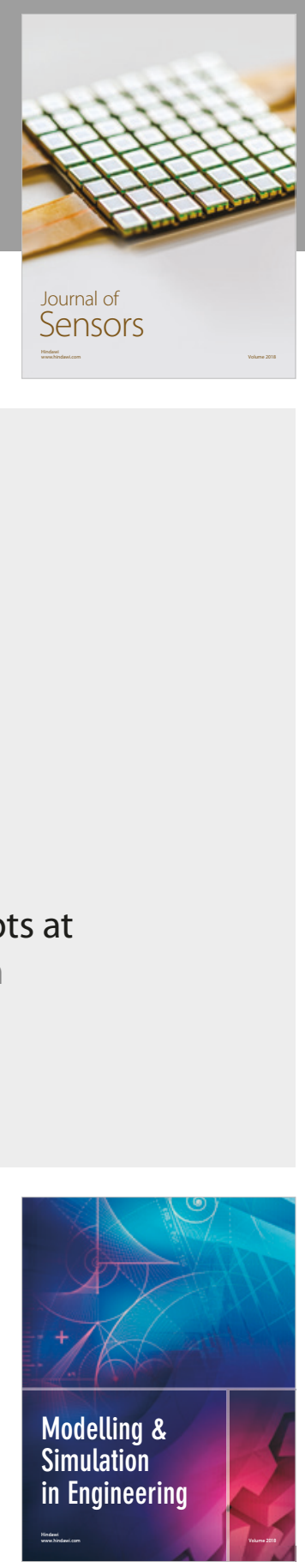

\section{Advances \\ Multimedia}
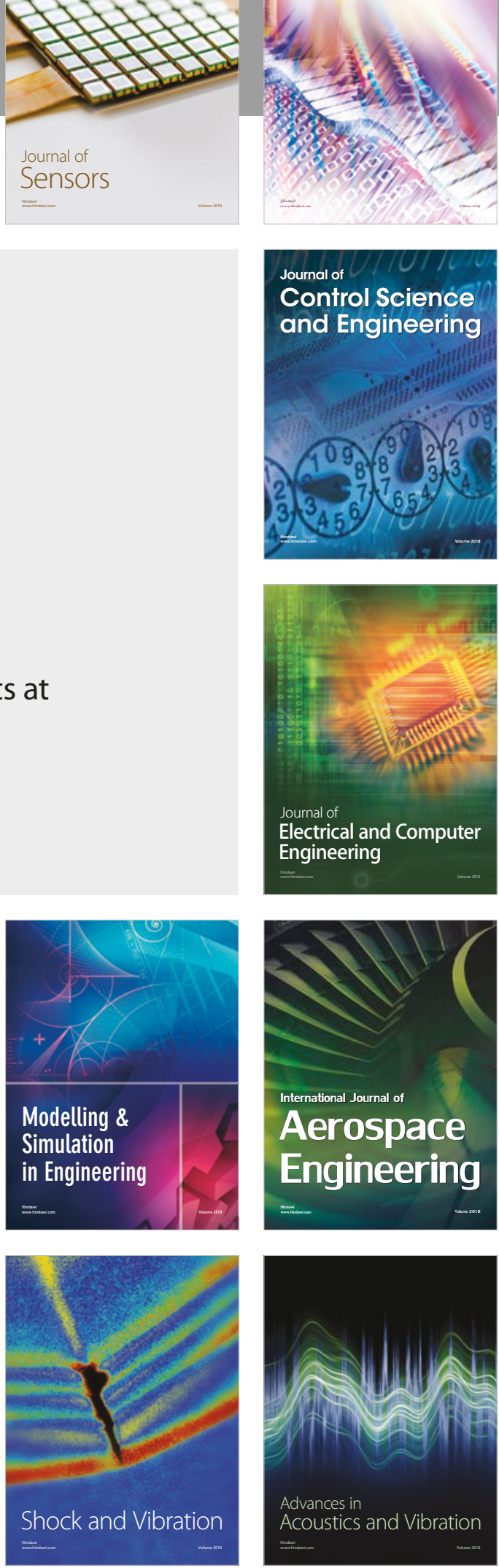